\title{
PERCEPÇÃO DE RISCOS NO TRABALHO: ESTUDO DE CASO COM COLABORADORES DE UMA INDÚSTRIA METALÚRGICA
}

\author{
Dener de Souza ${ }^{1}$, Ana Carla Fernandes Gasques ${ }^{2}{ }^{*}$, Maria de Lourdes Santiago Luz ${ }^{1}$, \\ ${ }^{1}$ Departamento de Engenharia de Produção, Universidade Estadual de Maringá, 87020-900, Maringá, Brasil.
}

*E-mail: anacarlafgasques@gmail.com

\section{RESUMO}

No cotidiano das organizações é comum a existência de riscos, que podem interferir na saúde do colaborador bem como no exercício de sua profissão. Dessa forma, a saúde e segurança de um indivíduo em seu ambiente de trabalho e as condições proporcionadas pela empresa refletem diretamente em sua produtividade e no bem-estar pessoal durante as ações que este exerce. Assim, este artigo tem como objetivo analisar a percepção de riscos no trabalho com colaboradores de uma metalúrgica localizada no noroeste do estado do Paraná. Adotou-se como metodologia a pesquisa exploratória e básica, implantada com o auxílio de questionário estruturado aplicado aos colaboradores. Para o desenvolvimento do artigo foram seguidas as etapas de elaboração da bibliografia, levantamento das informações e caracterização da empresa, coleta e análise dos dados, verificação dos equipamentos de segurança, elaboração da análise preliminar dos riscos e, por fim, proposição de melhorias para os riscos identificados pelos colaboradores. Como resultados os riscos presentes nos processos foram identificados com base na percepção dos colaboradores, dentre os quais destacam-se: utilização inadequada de EPIs, risco de quedas e intoxicação, bem como ruídos. A partir de então foram propostas melhorias. Desta forma foi possível concluir que as situações identificadas pelas análises trazem risco à segurança e saúde dos colaboradores desta empresa, devendo as mesmas receberem a devida atenção por parte dos responsáveis pela organização.

Palavras-chave: Segurança no trabalho. Análise de risco. Indústria Metalúrgica.

\section{Introdução}

O avanço tecnológico ocorrido a partir da revolução industrial permitiu que a produção aumentasse e houvesse uma transformação no ambiente de trabalho das organizações. Os prejuízos humanos, sociais e econômicos devido à falta de segurança em geral e consequentemente, ao elevado índice de acidentes, são altos para as empresas, trabalhadores e previdência social [1].

A segurança do trabalho é de interesse de toda a sociedade, visto que quando um trabalhador sofre um acidente com essa proporção, além do sofrimento pessoal pela incapacidade adquirida, ele desfalca o grupo de trabalho e passa a receber direitos previdenciários que são pagos por toda a sociedade [2]. A análise de risco tem sido uma das práticas mais utilizadas nos diferentes segmentos industriais como forma de evitar acidentes. Várias ferramentas podem estar associadas a essa análise, objetivando facilitar o estudo e melhor direcionamento das ações de controle.

Segundo Areosa e Dwyer [3] os riscos e os acidentes de trabalho sempre estiveram presentes nas empresas ao redor do mundo todo, alguns mais graves e fáceis de observar, com consequências imediatas e outros mais sutis, com os malefícios vindos à tona tempos depois. Os acidentes de trabalho ocorridos dentro de uma metalúrgica acontecem em sua maioria durante o processo de fabricação dos produtos metalúrgicos, como, ao cortar, dobrar, esmerilhar, soldar, ou também na instalação dos produtos produzidos, como quedas de altura, força excessiva, acidentes de trajeto.

Essa identificação dos possíveis riscos presentes, assim como uma análise preliminar dos riscos, é fundamental para que acidentes sejam evitados. O controle dos riscos e a prevenção de acidentes trazem inúmeros benefícios para os funcionários e para a empresa. Uma vez que o operário se sinta confortável e seguro em seu trabalho, identificando a preocupação da empresa com o seu bem-estar, ele ficará motivado para executar as suas atividades [4].

No Brasil os acidentes de trabalho aumentaram e mesmo atualmente é grande a quantidade de acidentes ocorridos, conforme consta no Anuário Estatístico da Previdência Social [5] em que no período entre os anos de 2013 e 2015, a quantidade de acidentes envolvendo os trabalhadores nas empresas somou o equivalente a mais de 2 milhões de ocorrências. Esses números 
aterrorizam, não apenas a previdência social, como as empresas envolvidas nesses acidentes.

Os acidentes de trabalho, além das perdas financeiras, interferem de forma direta na qualidade de vida do indivíduo acidentado, tendo em vista que este, além de ser afastado temporariamente do seu ambiente de trabalho, pode apresentar limitações futuras [4]. Outro ponto a ser ressaltado são as consequências à família da vítima, a qual tem seu rendimento mensal reduzido devido ao afastamento e maior demanda de recursos com os cuidados necessários pós-acidente.

Em uma empresa do ramo metalúrgico, os funcionários da área de produção trabalham atrelados constantemente a materiais pesados, máquinas de grande porte e a outros perigos eminentes, que, se forem desprezados, podem causar acidentes. Os acidentes de trabalho são causados basicamente quando se há um ato falho de descuido e falta de atenção do colaborador, bem como pelas condições precárias e elementos inseguros dos quais o mesmo possa estar sendo submetido no ambiente de trabalho [6].

Diante desse contexto, o artigo teve por objetivo geral analisar a percepção de riscos no trabalho com colaboradores de uma empresa metalúrgica localizada na cidade de Cianorte-Pr.

\section{Referencial Teórico}

O risco é uma tentativa de quantificar as possibilidades de violação e os prejuízos decorrentes do impacto de tal ação. Pode ser interpretada matematicamente como uma função da probabilidade de uma origem de ameaça, explorar uma vulnerabilidade potencial e do impacto resultante deste evento desencadeado adverso ao sistema, e consequentemente a empresa, e classificados de acordo com a natureza e a forma que atuam no organismo humano [7].

A avaliação de riscos é um dos aspectos mais importantes, senão o mais importante de qualquer estudo de segurança. No gerenciamento e avaliação dos riscos é fundamental identificar com precisão, os perigos potenciais no local de trabalho [8]. A gestão de riscos baseia-se em princípios e boas práticas de gerenciamento e segurança, para auxiliar na tomada de decisões. Um dos principais métodos para o auxílio no desenvolvimento do gerenciamento de riscos é o mapa de riscos onde é necessário conhecer o ambiente de trabalho, bem como o processo produtivo da empresa. Devem-se levar em conta também as características do funcionário: idade, sexo, número de trabalhadores e jornada de trabalho [9].

Segundo Lima e Lima [10] a análise preliminar de riscos é o estudo realizado durante a fase de projeto de um sistema, com a finalidade de identificar os riscos que podem estar presentes durante a fase operacional do mesmo. A Análise Preliminar de Riscos (APR) teve origem na área militar como revisão do sistema de mísseis. O risco é determinado pela probabilidade de que o dano ocorra e a gravidade potencial do dano.
A APR tem sido utilizada nas mais variadas áreas e situações, no entanto sua maior contribuição é na gestão de riscos. De acordo com França, Toze e Quelhas [6], o objetivo da APR é definir os riscos e as medidas preventivas antes da fase operacional, utilizando como metodologia a revisão geral de aspectos de segurança, através de um formato padrão, levantando as causas e efeitos de cada risco, medidas de prevenção ou correção e categorização dos riscos.

Dessa forma, entende a APR como um processo subdividido em etapas sequenciais, sendo que na revisão de problemas conhecidos busca-se por analogias ou similaridades com outros sistemas. Na etapa em que consta a revisão da missão a que se destina, atentar aos objetivos, exigências de desempenho, principais funções e procedimentos, estabelecer os limites de atuação e delimitar o sistema [11].

A determinação dos riscos principais visa apontar os riscos com potencialidade para causar lesões diretas imediatas, perda de função, danos a equipamentos e perda de material, e subdivide-se na revisão dos meios de eliminação ou controle de riscos, para estabelecer as melhores opções compatíveis com as exigências do sistema, analisar os métodos de restrição de danos encontrar métodos possíveis e eficientes para a limitação dos danos gerados pela perda de controle sobre os riscos, indicação de quem levará a sério as ações corretivas e/ou preventivas [11]

Com base nas referências supracitadas, determina-se que a aplicação da APR na empresa estudada seguirá as etapas de maneira a examinar as formas pelas quais as atividades são realizadas, levantando para cada um dos riscos de acidente, físicos, químico e ergonômicos identificados, as suas causas, os efeitos sobre os trabalhadores, a frequência, a severidade e o nível de riscos, de acordo com as Tabelas 1 a 4 abaixo. Em seguida é feita uma avaliação qualitativa dos riscos associados, identificando-se, desta forma, aqueles que requerem priorização. Posteriormente são sugeridas medidas preventivas dos riscos a fim de eliminar as causas ou reduzir as consequências dos cenários de acidente identificados [12].

Frente a este contexto, torna-se necessário identificar possíveis medidas preventivas e sua eficácia com o auxílio dos próprios atores de dentro do processo, no caso os colaboradores, identificando medidas preventivas que agregaram no desenvolvimento das atividades diárias, propondo, com base nas normas e regulamentos analisados neste estudo, melhorias que possam ser implantadas pela empresa [13].

\section{Metodologia}

Quanto à natureza da pesquisa, a presente metodologia se caracteriza, de acordo com Gil [14], como básica ou fundamental, tendo em vista que seus dados geram informações para a solução de problemas, envolvendo interesses reais e propiciando novos conhecimentos acerca de um determinado tema. Em relação à abordagem adotada, será de cunho qualitativo, onde se prioriza as 
análises e interpretações do contexto de maneira geral, e não de dados quantitativos [14].

$\mathrm{Na}$ definição dos objetivos, a pesquisa é tida como exploratória, onde os processos serão analisados, aproveitando-se do fato da familiaridade já existente com o problema, visando torná-lo explícito e construir hipóteses sobre sua problemática. No que tange aos procedimentos técnicos, o trabalho é um estudo de caso, onde pesquisador e participantes interagem para analisar e solucionar problemas reais de maneira organizada, explicativa e empírica, abordando um fenômeno dentro do contexto do dia a dia [14].

Ainda segundo Gil [14], para coleta de dados podem ser utilizadas técnicas de interrogação: o questionário, a entrevista e o formulário.

Para o desenvolvimento inicial a revisão bibliográfica dos conceitos relacionados ao estudo (Segurança do Trabalho, Normas Regulamentadoras, Gerenciamento de Riscos e Análise Preliminar dos Riscos) é o principal ponto de partida das análises.

O levantamento das informações, dados dos processos e dos trabalhadores executores das atividades são obtidos através da observação e de entrevistas com a utilização de um questionário com 11 questões (Apêndice A), realizadas com os 12 colaboradores da empresa no período de 1 semana, entre os dias 10 e 15 de setembro de 2017, gerando subsídios para o andamento da pesquisa. Para a aplicação deste questionário foi proposto a todos os colaboradores a análise e assinatura do Termo de Consentimento Livre e Esclarecido (Apêndice B), informando a todos as reais motivações para a execução desta pesquisa, bem como seus desdobramentos, benefícios e objetivos buscados.

A caracterização da empresa foi realizada por meio de observação direta do espaço físico disponível e do ambiente de trabalho dispostos aos colaboradores. Os dados foram analisados com auxílio de gráficos confeccionados para facilitar o entendimento quanto às informações quantitativas.

A análise preliminar dos riscos foi realizada a partir de uma pré-análise no ambiente de trabalho da empresa, com intuito de conhecer a rotina do processo, na qual foram realizadas visitas a empresa, para observar e adquirir conhecimentos relativos às etapas do processo produtivo e familiarização com a rotina da organização. A confrontação direta com os colaboradores e a observação de cada envolvido também foi essencial para o desenvolvimento da ferramenta, pois são as opiniões, percepções e detalhamentos de cada colaborador que nutre a pesquisa realizada.

No desenvolvimento da APR foram estabelecidas em colunas e linhas os riscos, causa, efeito, categoria de frequência, categoria de severidade, categoria de risco. Para a aplicação da APR utilizaram-se tabelas de classificação da severidade dos riscos. De acordo com a metodologia de APR adotada neste trabalho, os cenários de acidentes devem ser classificados em categorias de frequência, as quais fornecem uma indicação qualitativa da frequência esperada de ocorrência para cada um dos cenários identificados [12].

Com relação à severidade, divide-se em: I - Desprezível, II - Marginal, III - Crítico e IV - Catastrófico. A classificação dos níveis de risco, que se trata do resultado da combinação entre a frequência e severidade é apresentada na Tabela 1 a seguir. A matriz dos níveis de risco fornece uma indicação qualitativa do nível de risco de cada cenário identificado, permitindo visualizar os cenários de maior impacto para a segurança do colaborador.

Tabela1 - Combinação de Frequência e Severidade, fonte [12].

\begin{tabular}{lllllll}
\hline & IV & M & M & NT & NT & NT \\
\cline { 2 - 7 } SEVERIDADE & III & T & M & M & NT & NT \\
\cline { 2 - 7 } & II & T & T & M & M & M \\
\cline { 2 - 7 } & I & T & T & T & T & M \\
\cline { 2 - 7 } & & A & B & C & D & E \\
\cline { 2 - 6 } & & &
\end{tabular}

Cada denominação de severidade, como catastrófico, crítico, marginal, e desprezível, será caracterizada por um símbolo (IV, III, II, I) e irá se relacionar com um nível de risco, não tolerável (NT), moderado (M) e tolerável (T) e com as letras A, B, $\mathrm{C}, \mathrm{D}$ e $\mathrm{E}$, que representam as denominações de frequência (frequente, provável, pouco provável, remota e extremamente remota).

A Tabela 2 apresenta a descrição de cada categoria de risco, informando os métodos e medidas que podem ser tomados para controlar e prevenir os riscos encontrados no estudo.

Tabela 2 - Descrição dos níveis de risco fonte [12].

\begin{tabular}{ccl}
$\begin{array}{c}\text { Nível } \\
\text { de } \\
\text { Ruído }\end{array}$ & Denominação & \multicolumn{1}{c}{ Descrição } \\
\hline NT & Não tolerável & $\begin{array}{l}\text { Os controles existentes são insuficientes. } \\
\text { Métodos alternatvos devem ser considerados } \\
\text { para reduzir a probabilidade de ocorrência e, } \\
\text { adicionalmente, as consequências de forma a } \\
\text { trazer os riscos para regiões de menor } \\
\text { magnitude de riscos. }\end{array}$ \\
& Moderado & $\begin{array}{l}\text { Controles adicionais devem ser avaliados } \\
\text { com objetivo de obter-se uma redução dos } \\
\text { riscos e implementados aqueles considerados } \\
\text { praticáveis. }\end{array}$ \\
\hline M & & $\begin{array}{l}\text { Não há necessidade de medidas adicionais. } \\
\text { Monitoramento é necessário para assegurar } \\
\text { que os controles sejam mantidos. }\end{array}$ \\
\hline
\end{tabular}

Analisando as Tabelas 1 e 2 é possível constatar que é necessário conhecer o processo de trabalho no local analisado, identificar as etapas das ações desenvolvidas na empresa, a mão de obra utilizada em cada momento, os processos de input e output, os artefatos que são mais vendidos, a matéria prima utilizada, a disposição do espaço físico (layout) além da disposição de máquinas e equipamentos [12]. 
Posteriormente, é aplicada a ferramenta $5 \mathrm{~W} 1 \mathrm{H}$, que com base nos riscos identificados nas análises das percepções dos colaboradores e na análise preliminar de riscos, propõe medidas preventivas dos riscos a fim de eliminar as causas ou reduzir as consequências dos cenários de acidente.

A ferramenta $5 \mathrm{~W} 1 \mathrm{H}$ tem como objetivo auxiliar na ação com a obtenção de respostas que esclareçam o problema a ser resolvido por meio de perguntas simples e diretas, sendo: What? (O quê? representando aquilo que deve ser feito); Who (Quem?, indicando o responsável pela ação); Where (Onde?, a fim de especificar o local onde ação será desenvolvida); When? (Quando?, onde estabelece-se o prazo), Why (Por quê? justificando-se a necessidade da ação) e a palavra How (Como?) representa a forma com a qual será desenvolvida determinada ação. De forma geral, estabelece-se um plano de ação para atividades estabelecidas previamente [15].

A utilização desta ferramenta permite dividir o processo em etapas a serem seguidas, de modo organizado, determinando e especificando cada ponto, de modo que seja de fácil compreensão para qualquer pessoa que a manipule ou analise. Esse modelo é empregado em projetos em que não serão dispendidos recursos para sua execução ou serão utilizados materiais, equipamentos ou força de trabalho presentes no próprio local [15].

A elaboração do Plano de ação a partir do $5 \mathrm{~W} 1 \mathrm{H}$ foi feita com o auxílio do responsável da organização, tendo em vista que o plano precisa ser desenvolvido de acordo com a realidade da organização.

\section{Resultados e discussões}

\subsection{Caracterização da empresa}

A empresa estudada é uma metalúrgica localizada no noroeste do estado do Paraná especializada no ramo de serralheria, produzindo grades, portões, estruturas metálicas, utilizando como matéria prima, principal o ferro, proveniente das mais diversas siderúrgicas nacionais e internacionais.

Suas instalações estão em um ponto comercial com espaço físico total de $400 \mathrm{~m}^{2}$, divididos em setor administrativo, setor de produção, setor de pintura, cozinha e banheiro. As máquinas estão dispostas de maneira aleatória no setor de produção, sendo elas uma dobradeira de calhas, uma máquina de tela e alambrado, uma prensa hidráulica, uma lixadeira, um policorte, três máquinas de solda, um esmeril, uma furadeira de bancada. Já no setor de pintura são utilizados dois compressores de ar e duas pistolas de pintura.

A empresa conta com um quadro de funcionários compostos de 12 pessoas, com variados níveis de experiência em suas respectivas funções, entretanto todos passam pelo período de treinamento e pelo contrato de experiência para iniciar suas atividades dentro da empresa. No setor administrativo tem-se o diretor, o gerente de produção, o vendedor e o auxiliar administrativo. No setor da produção encontram-se quatro soldadores/serralheiros, um calheiro, um auxiliar de calheiro, e no setor de pintura trabalham um pintor e um auxiliar de pintor.

O diretor, que é o proprietário da empresa, comanda as operações, passando as metas e objetivos traçados pela empresa para o todo o setor administrativo. $\mathrm{O}$ vendedor busca angariar novos clientes e gerar novos pedidos diariamente, emitindo as ordens de produção ao setor de produção quando este for bemsucedido.

O gerente de produção é responsável por acompanhar todas as ações no setor de produção bem como analisar estoques, lead time e conclusão e entrega dos pedidos realizados. $\mathrm{O}$ auxiliar administrativo é responsável por toda a questão burocrática que envolve a parte financeira da empresa, como emissão de boletos, notas fiscais, e cobrança junto aos clientes. Este é responsável também pela elaboração dos pedidos de matéria-prima, seguindo um relatório enviado pelo gerente de produção com as necessidades do setor.

Foi possível analisar por meio de observação direta que o Soldador/Serralheiro é o único que opera nessa função, porém ele não fica retido apenas a ela, exercendo também as atividades voltadas à produção dos pedidos como corte, polimento, prensamento. Por outro lado, ele é o único funcionário que opera a solda, sendo que os demais trabalhadores não executam essa função. Essa característica se aplica para os outros funcionários, onde o Pintor também executa serviços de Calheiro, uma vez que o serviço de pintura ocorre poucas vezes durante o dia.

As funções executadas por cada funcionário da empresa são as seguintes: Soldador realiza a solda, o corte e o polimento. O serralheiro realiza o corte, o polimento a montagem e instalação dos produtos fabricados. O pintor faz a pintura, o lixamento dos produtos. O calheiro realiza a medição no local do serviço, o corte e dobra da matéria prima e sua instalação final.

De acordo com o questionário, $59 \%$ dos colaboradores da empresa estão na faixa etária de 20 a 30 anos, $33 \%$ na faixa dos 30 a 40 anos, $8 \%$ na faixa de 40 a 50 anos (Figura 1). 


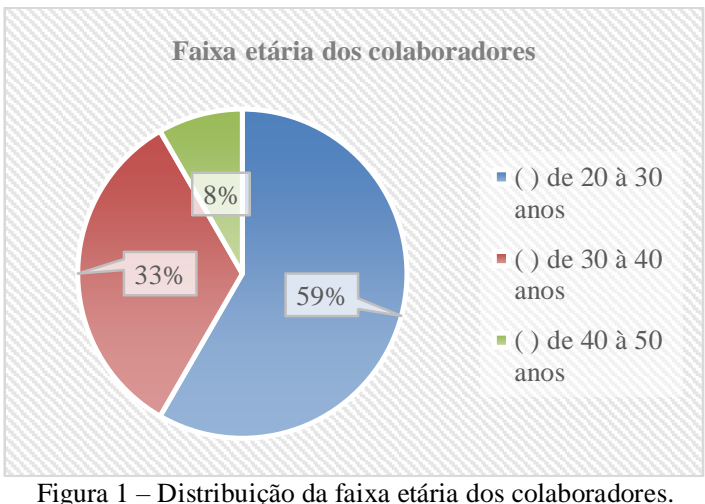

Na faixa etária de 16 a 20 anos, bem como acima dos 50 anos não há colaboradores. Além disso, foi constatado' que os colaboradores do setor de produção e pintura possuem idade entre 20 e 38 anos, sendo 6 destes abaixo dos 30 anos de idade, que pode ser explicado pelo fato dos setores requererem grande esforço físico e agilidade nas funções.
O setor administrativo, em contrapartida, conta com funcionários acima de 30 anos. O diretor é o indivíduo mais velho da empresa com 46 anos de idade e o auxiliar de calheiro o mais novo com 21 anos de idade. Percebe-se na Figura 2, que no estudo que cada funcionário tem no mínimo 3 anos de experiência no ramo metalúrgico.

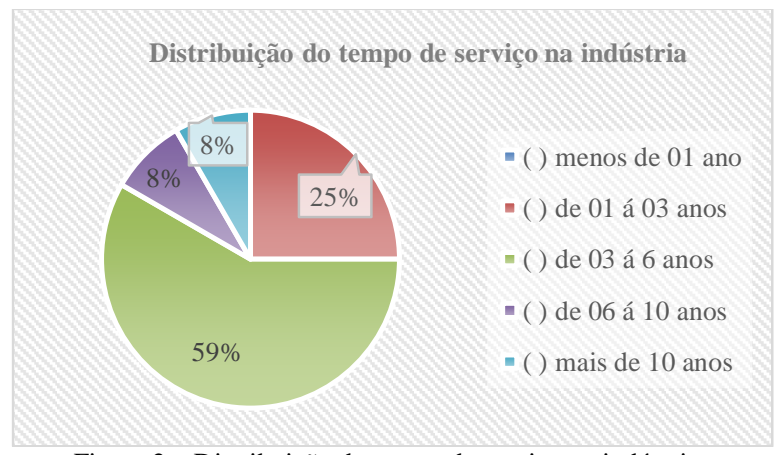

Figura 2 - Distribuição do tempo de serviço na indústria.

O colaborador com mais tempo de serviço prestado a empresa é o gerente de produção, com mais de 12 anos de registro no quadro de funcionários. A maior porcentagem observada é referente aos trabalhadores com entre 3 e 6 anos de experiência, seguido por aqueles com experiência de 1 a 3 anos (59 e 25\% respectivamente. Os trabalhadores com experiência entre 6 a 10 anos ou acima de 10 anos representaram $8 \%$, cada. Nenhum colaborador tem menos de 03 anos na indústria metalúrgica.

\subsection{Percepção dos riscos}

Com a aplicação do questionário junto aos 12 colaboradores da empresa, somado à observação dos processos produtivos têm-se subsídios para realizar a análise preliminar de riscos, onde pode-se identificar os riscos presentes nas operações e no andamento do processo.

Com as respostas ao questionário visualizou-se que dos 8 colaboradores de ambos os setores produtivos, 5 afirmaram ter sofrido algum tipo de acidente de trabalho, sendo que 3 destes foram dentro da empresa estudada, como pôde ser ilustrada na Figura 3, onde caracteriza-se que $62 \%$ já sofreram acidentes e outros $38 \%$ nunca se acidentaram no trabalho.

A maior incidência foi na utilização da máquina de corte chamada lixadeira, onde é comum verificar casos de discos utilizados estourarem e ferirem seus operadores.

Sobre sentir-se desprotegidos nas atividades do dia a dia, apenas o Calheiro e seu auxiliar confirmaram positivamente a esta questão, pois são os que mais exercem funções com a máquina dobradeira de calhas, recorrente quando o assunto é ferimentos nas mãos, incluindo também o desgaste diário causado pela exposição ao sol. Assim, $83 \%$ dos colaboradores não se sentem desprotegidos no andamento das atividades, enquanto $17 \%$ afirmam sentir-se desprotegidos. Outro fato importante sobre essa afirmação é a situação enfrentada nas instalações dos produtos produzidos por eles, que comumente ocorrem em ambientes com altura, e grande exposição aos raios ultravioletas emitidos pelo sol.

Com relação ao ambiente ou qual máquina lhe causam mais precaução todos foram enfáticos ao apontar que a lixadeira é o 


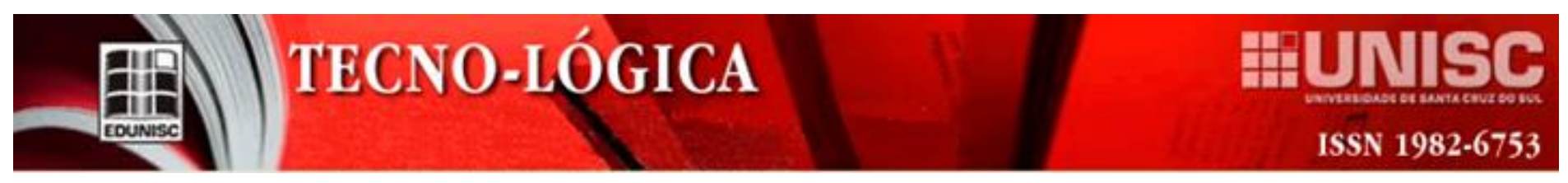

equipamento mais perigoso do processo. $\mathrm{O}$ policorte que também tem o mesmo tipo funcionamento e tem a mesma função de serrar a matéria prima e as máquinas de solda que emitem altos níveis de gases tóxicos e que necessita de alto grau de experiência para ser manuseada, são as outras máquinas que mais causam temor e preocupação durante o andamento do processo produtivo da empresa.

O calor enfrentado dentro da empresa durante a realização do trabalho é outro fator recorrente de preocupação, as instalações da empresa possuem pouca ventilação o que prejudica até mesmo a respiração nos padrões normais de qualquer pessoa que lá esteja. Todos os colaboradores avaliam de forma positiva a prestação de serviço no que diz respeito a segurança no trabalho dentro da indústria, porém opinam que cursos profissionalizantes e informativos poderiam ser ofertados com frequência pela empresa.

Ao serem abordados sobre as situações críticas que enfrentavam todos os dias, $75 \%$ relataram que o conforto térmico é o empecilho maior, seguido por ruídos, esforço físico e falta de manutenção com 66\% (Figura 4).

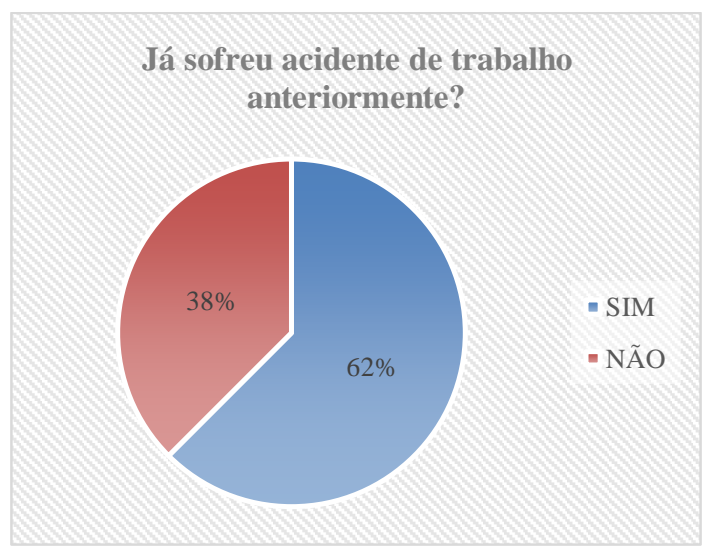

Figura 3 - Números de colaboradores que já sofreram acidentes no trabalho.

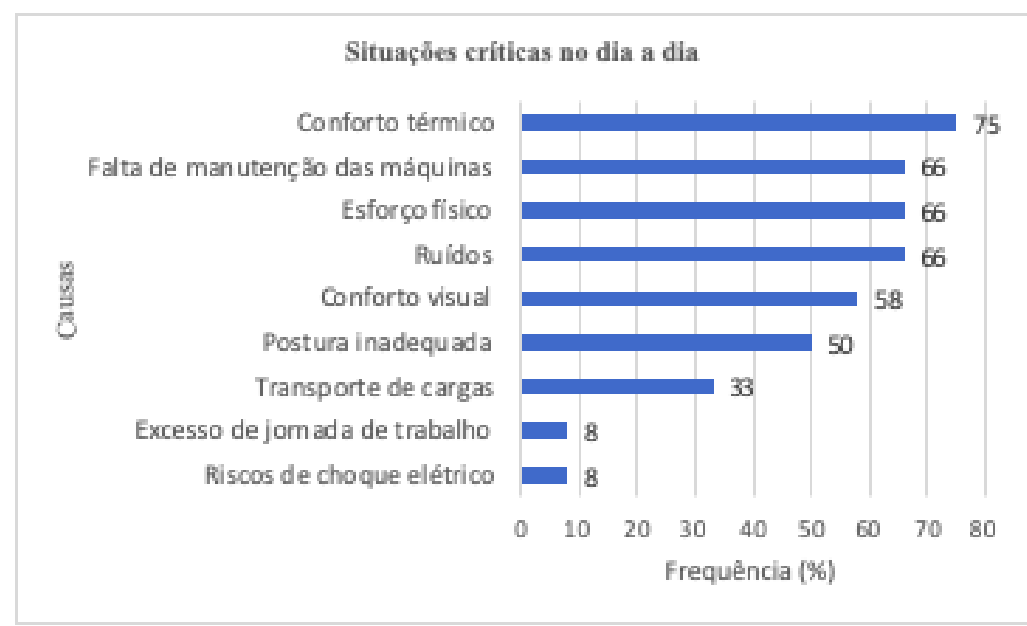

Figura 4 - Situações críticas vivenciadas no cotidiano.

A partir da Figura 4, entende-se que 58\% dos colaboradores indicam sua percepção de riscos ao conforto visual no trabalho, posteriormente $50 \%$ determinam que a postura inadequada é uma situação crítica. Dos colaboradores $33 \%$ dizem que o transporte de material é uma situação crítica, e $8 \%$ classificam tanto possíveis choques elétricos quanto a jornada excessiva de trabalho, outras situações criticam do dia a dia da empresa. Nesta distribuição de situações críticas vivenciadas no dia a dia, os colaboradores poderiam escolher mais de uma opção como sendo uma atividade prejudicial no andamento de suas funções.

A empresa fornece a seus operários determinados EPIs, de acordo com a NR 6, onde esses equipamentos ficam à disposição dos funcionários, próximo ao posto de trabalho que se 


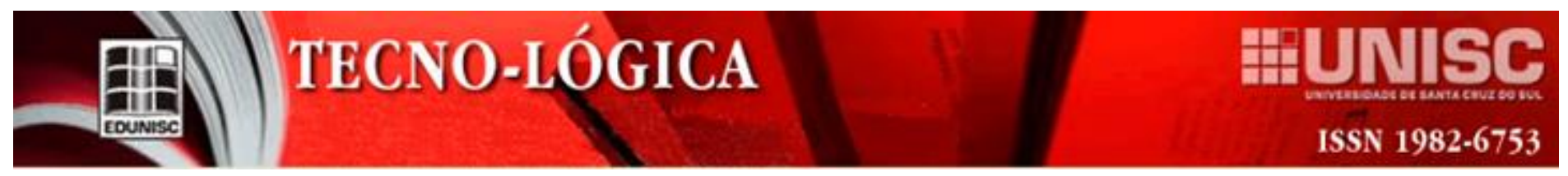

faz necessário o uso deste. Ao serem questionados sobre a opinião acerca do que poderia ser melhorado para eliminar ou evitar os riscos presentes na empresa, todos confirmaram que é necessário o uso dos EPIs a todo instante. Porém confirmaram que raramente fazem o seu uso de forma correta, pois se sentem limitados tanto em sua agilidade quanto em sua disposição.

Dos colaboradores entrevistados, 5 responderam à questão número 11 do questionário proposto que fala sobre o que poderia ser melhorado para evitar ou eliminar os riscos de sua função e da empresa, citando a automatização de algumas máquinas na empresa como a dobradeira e a prensa hidráulica, bem como uma melhora do espaço físico e da iluminação disponível no ambiente.

Os EPIs disponibilizados e que estavam presentes dentro do processo da metalúrgica são os representados nas Figuras 5. A Figura 5a apresenta os óculos de proteção para corte, usado nas atividades envolvendo ferramentas de corte, de lixamento, fundamental para evitar que os riscos causados pela utilização destes equipamentos, se tornem acidentes, tanto que 58\% dos colaboradores citam o conforto visual como uma problemática na empresa.

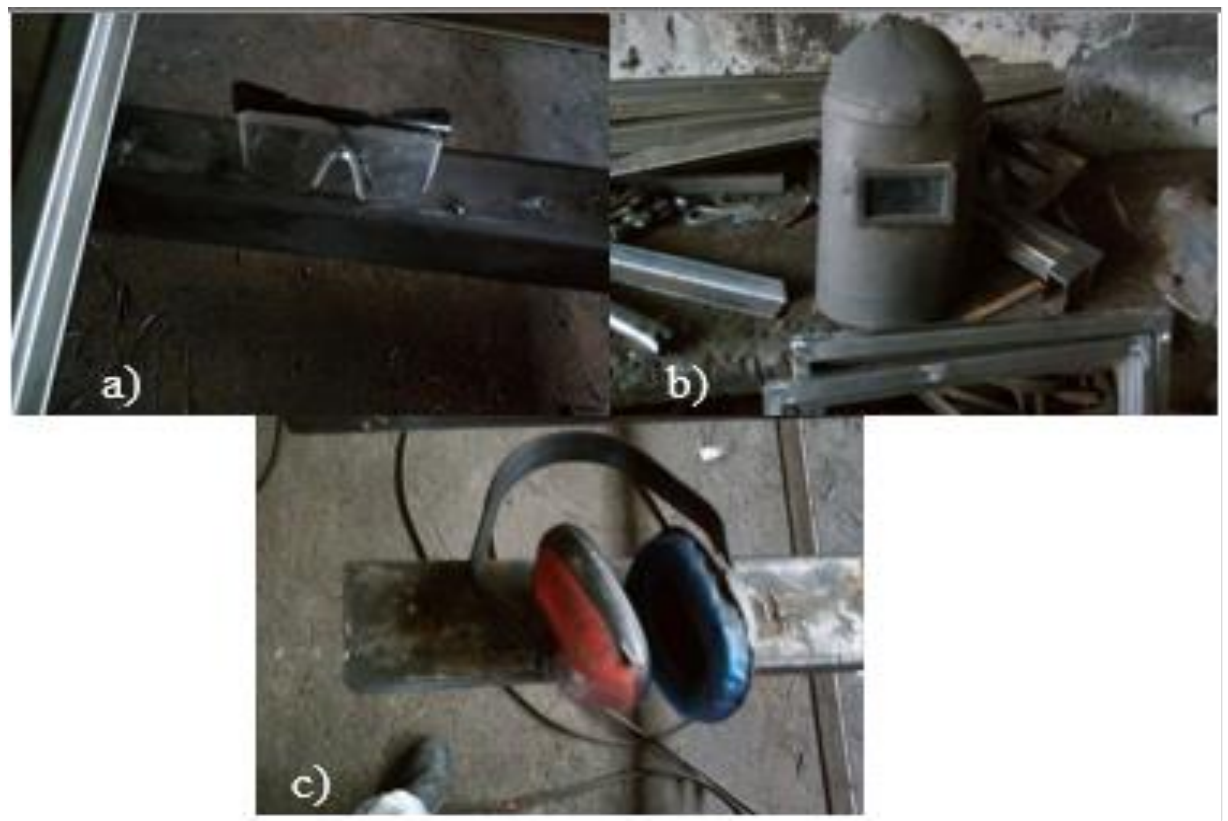

Figura 5 EPIs - a) Óculos de proteção b) Máscara de solda c) Protetor auricular.

Especificamente para os produtos soldados, existe o risco de queimadura e de inalação de fumos durante o processo de soldagem, além de poder causar danos a visão dos trabalhadores. Para evitar que acidentes aconteçam, é recomendado que, além das luvas, também sejam utilizadas máscaras, para que os fumos não sejam inalados, e a utilização da máscara de solda, para proteger os olhos dos trabalhadores da forte luz emitida durante o processo.

Assim, a máscara de solda (Figura 5b) é um dos EPIs mais importantes fornecidos na empresa. É utilizado no processo de soldagem, e é fundamental para evitar que os raios e fumos tóxicos emitidos pela solda afetem a visão dos colaboradores. A máscara deve ser de material resistente e com vidro escuro, pois sua qualidade afeta a durabilidade da máscara. A Figura $5 \mathrm{c}$, mostra um dos protetores auriculares estilo fone utilizados pelos colaboradores.

Pode-se observar que é um EPI de grande tempo de uso devido ao seu estado de conservação, além disso, é um item fundamental tendo em vista que $66 \%$ dos colaboradores citam os ruídos emitidos como uma situação crítica do dia a dia.

Analisando o processo de trabalho da empresa, visando reconhecer outros riscos aos colaboradores durante as operações das atividades, com o apoio do questionário realizado conclui-se que o transporte da matéria-prima ou do produto sendo processado, é realizado de modo manual, sem o auxílio de máquinas ou equipamentos. Isso faz com que os trabalhadores possam se machucar com farpas das ferragens ou se cortar com pontas e cantos das peças de metal.

Para o setor de pintura existem os riscos do trabalho em altura e da intoxicação pelo pó da tinta ou pelo pó do lixamento do produto que antecede a pintura. Outro risco inerente a este setor, diz respeito ao transporte desses materiais, o que torna uma possível queda do mesmo, podendo atingir os pés ou outros membros dos trabalhadores.

Durante o processamento, a matéria-prima passa por um processo de corte e lixamento, podendo ser pelo policorte, prensa 


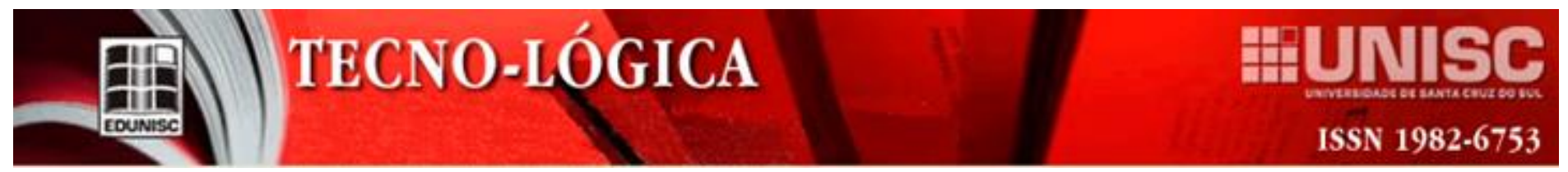

hidráulica e lixadeira. Os riscos durante a execução destas funções são alto, onde são equipamentos elétricos de alta rotação e com peso considerável, que caso haja um acidente, como a quebra de um disco, o voo de faíscas que queimam a pele e podem atingir os olhos, os ruídos emitidos, as consequências são graves. Nesses processos é essencial que o operário utilize alguns equipamentos de proteção, como luvas e óculos de proteção. Esses equipamentos protegem o trabalhador da projeção de partículas nos olhos e nas mãos.

\subsection{Análise preliminar de riscos}

O desenvolvimento da APR foi feito para cada setor produtivo da empresa, sendo: setor de pintura, serralheria, soldagem e calha, baseando-se nas respostas adquiridas com os colaboradores.

No setor de pintura (Tabela 3) foi identificado um risco químico devido a poeira, com frequência provável, com grau de severidade crítico e nível de risco não tolerável. Foi visualizado também o risco ergonômico com frequência provável, grau de severidade crítico e nível de risco não tolerável e o risco de acidentes do com frequência provável, com grau de severidade crítico e nível de risco não tolerável.

A Tabela 4 representa o setor de serralheria, onde foi identificado risco físico, ergonômico e de acidentes. Risco físico foi observado como sendo todo o ruído presente no setor, com categoria de frequência (E) frequente, grau de severidade crítico e nível de risco não tolerável. Quanto ao risco ergonômico se dá pela razão de que o transporte e manuseio do material são inteiramente realizados de forma manual, expondo o funcionário ao esforço físico e iminentes lesões e desconforto, sendo categoria de frequência (D) provável, grau de severidade crítico e nível de risco não tolerável.

Tabela 3-APR Setor de pintura.

\begin{tabular}{|c|c|c|c|c|c|}
\hline \multicolumn{6}{|c|}{ 01 - APR SETOR PINTURA } \\
\hline RISCO & CAUSA & EFEITO & FREQ. & SEV. & N.R. \\
\hline Acidente & Queda de altura & Ferimentos & $\mathrm{D}$ & III & NT \\
\hline Químico & Poeira & Intoxicação & $\mathrm{D}$ & III & NT \\
\hline Ergonômico & $\begin{array}{l}\text { Levantamento } \\
\text { transporte de } \\
\text { materiais pesados }\end{array}$ & $\begin{array}{l}\text { Dores } \\
\text { musculares }\end{array}$ & $\mathrm{D}$ & II & M \\
\hline
\end{tabular}

Tabela 4 - APR Setor de serralheria.

\begin{tabular}{llllll}
\hline \multicolumn{7}{c}{ 02 - APR SETOR SERRALHERIA } & & \\
\hline RISCO & CAUSA & EFEITO & FREQ. & SEV. & N.R. \\
\hline Acidente & $\begin{array}{l}\text { Máquinas } \\
\text { proteção adequada }\end{array}$ & Ferimentos & D & III & NT \\
\hline Físico & Ruído & $\begin{array}{l}\text { Problemas } \\
\text { auditivos }\end{array}$ & E & III & NT \\
\hline Ergonômico & Esforço físico & $\begin{array}{l}\text { Dores } \\
\text { musculares }\end{array}$ & D & II & M \\
\hline
\end{tabular}

O risco de acidente devido a equipamentos sem proteção pode gerar gravíssimas consequências aos trabalhadores que o operam, como por exemplo, cortes, mutilações, lacerações, etc., o que na APR o torna categoria de frequência (D) provável, grau de severidade crítico e nível de risco não tolerável.

As imagens das máquinas citadas nas respostas dos colaboradores e expressas acima no APR do setor de serralheria como sendo as mais preocupantes e suscetíveis a causar acidentes de trabalho estão apresentas na Figura 6.

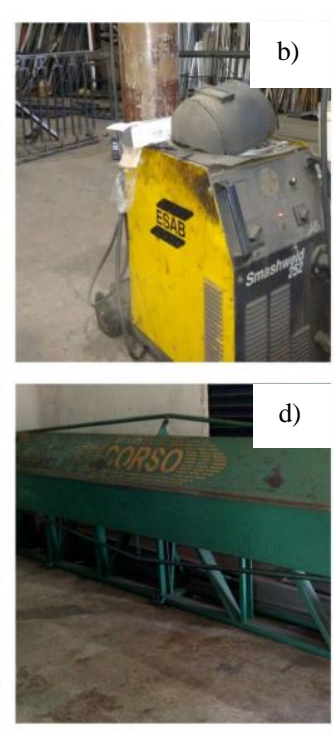

Figura 6- Máquinas com riscos de acidentes. a) policorte. b) máquina de solda. c) Lixadeira de bancada. d) Dobradeira de calha. 
No primeiro quadrante o policorte, com tempo de utilização razoavelmente pequeno, em torno de 4 anos, porém suas manutenções nunca foram realizadas. No segundo quadrante temse um modelo de máquina de solda presente na empresa, são 3 no total, essa é a mais potente, que consegue atingir a maior amperagem, portanto mais perigosa do que as demais.

No terceiro quadrante um modelo de lixadeira utilizada nos processos de fabricação da empresa, também perigosa e que requer grandes cuidados ao ser manuseado. E por fim no quarto quadrante visualiza-se a dobradeira de calhas, uma máquina com o comprimento total de 6 metros, extremamente difícil de realizar sua instalação, com alto grau de risco, entretanto apesar de seu peso e modo de funcionamento é uma máquina de fácil utilização.

$\mathrm{O}$ setor de soldagem apresentou riscos físicos, ergonômicos, de acidentes e químicos (Tabela 5) O risco físico foi considerado devido aos ruídos emitidos pelo processo de soldagem. Já o risco ergonômico foi identificado devido ao esforço físico em se manter o objeto na mesma posição para montar o produto e também a postura inadequada que o trabalhador está sujeito durante a execução da atividade.

$\mathrm{Na}$ APR o risco físico é na categoria de frequência, frequente $(\mathrm{E})$, grau de severidade crítico (III) e nível de risco não tolerável (NT). Já o risco ergonômico caracteriza-se por ser na categoria de frequência (D) provável, grau de severidade crítico (III) e nível de risco não tolerável (NT).

Tabela 5 - APR do setor de soldagem.

\begin{tabular}{llllll}
\hline \multicolumn{2}{c}{ 03 - APR SETOR SOLDAGEM } & & \\
\hline RISCO & CAUSA & EFEITO & FREQ. & SEV. & N.R. \\
\hline Acidente & Incêndio, explosões & Ferimentos & D & III & NT \\
\hline Físico & Ruído & $\begin{array}{l}\text { Problemas } \\
\text { auditivos }\end{array}$ & E & III & NT \\
\hline Ergonômico & $\begin{array}{l}\text { Esforço físico, } \\
\text { postura inadequada }\end{array}$ & $\begin{array}{l}\text { Dores } \\
\text { musculares }\end{array}$ & D & II & NT \\
\hline Químico & Fumo de solda & $\begin{array}{l}\text { Intoxicação } \\
\text { respiratória }\end{array}$ & C & II & M \\
\hline
\end{tabular}

Foram ainda identificados outros dois riscos para o setor de soldagem: químico, pela presença do fumo de solda, sendo (C) pouco provável, de severidade marginal (II) e nível de risco moderado (M), e de acidentes, devido ao fato de que a solda pode causar incêndio ou explosões, categoria de frequência (D) provável, grau de severidade crítico e nível de risco não tolerável.

No setor de calha (Tabela 6), foram identificados riscos físicos, riscos ergonômicos, riscos químicos e riscos de acidentes. O risco físico se justifica pela alta exposição ao sol do colaborador, onde segundo a APR é categoria de frequência (E) frequente, grau de severidade crítico e nível de risco não tolerável.

$\mathrm{O}$ risco ergonômico se dá pelo esforço físico e pela postura inadequada ao utilizar os equipamentos e máquinas úteis para o desenvolvimento das atividades, caracterizando categoria de frequência (D) provável, grau de severidade crítico e nível de risco não tolerável. Já o risco químico foi considerado (C) pouco provável devido a poucas vezes que o pó de ferro, que é uma composição química que se desprende da matéria prima utilizada. É considerado de severidade marginal (II) e nível de risco moderado $(\mathrm{M})$.

Tabela 6 - APR do setor de calha.

\begin{tabular}{llllll}
\hline \multicolumn{7}{c}{ 03 - APR SETOR CALHA } \\
\hline RISCO & CAUSA & EFEITO & FREQ. & SEV. & N.R. \\
\hline Acidente & $\begin{array}{l}\text { Quedas de altura ou } \\
\text { de objetos }\end{array}$ & Ferimentos & D & III & NT \\
\hline Físico & Sol & $\begin{array}{l}\text { Problemas } \\
\text { na pele }\end{array}$ & E & III & NT \\
\hline Ergonômico & $\begin{array}{l}\text { Esforço físico, } \\
\text { postura inadequada }\end{array}$ & $\begin{array}{l}\text { Dores } \\
\text { musculares }\end{array}$ & D & III & NT \\
\hline Químico & Pó de ferro & $\begin{array}{l}\text { Intoxicação } \\
\text { respiratória }\end{array}$ & C & II & M \\
\hline
\end{tabular}

O risco de acidentes é considerado categoria de frequência (D) provável, grau de severidade crítico e nível de risco não tolerável, pois pode haver acidentes durante o manuseio de máquinas e equipamentos sem proteção adequada, durante a instalação do produto acabado, como quedas, cortes, acidentes que podem ser terrivelmente prejudiciais à saúde e ao bem-estar do colaborador e que devem ser monitoradas para que não possam se tornar realidade.

Na Tabela 7, tem-se a distribuição dos riscos encontrados por setor através da percepção dos colaboradores e identificados na APR, que deve ser utilizado em uma futura elaboração do mapa de riscos.

\begin{tabular}{|c|c|c|c|c|}
\hline SETOR & RISCO FIS. & $\begin{array}{l}\text { RISCO } \\
\text { QUIM. }\end{array}$ & $\begin{array}{l}\text { RISCO } \\
\text { ERGO. }\end{array}$ & $\begin{array}{l}\text { RISCO DE } \\
\text { ACID. }\end{array}$ \\
\hline PINTURA & Altura & Poeira & $\begin{array}{l}\text { Postura } \\
\text { inadequada, } \\
\text { transporte de } \\
\text { peso }\end{array}$ & $\begin{array}{l}\text { Queda de } \\
\text { altura e de } \\
\text { objetos }\end{array}$ \\
\hline SERRALHERIA & Corte & $\begin{array}{l}\text { Não } \\
\text { encontrado }\end{array}$ & $\begin{array}{l}\text { Esforço } \\
\text { físico, } \\
\text { transporte } \\
\text { manual e de } \\
\text { peso }\end{array}$ & $\begin{array}{l}\text { Máquinas e } \\
\text { equipamentos } \\
\text { sem proteção } \\
\text { adequada }\end{array}$ \\
\hline SOLDAGEM & Queimaduras & $\begin{array}{l}\text { Fumo de } \\
\text { solda }\end{array}$ & $\begin{array}{l}\text { Esforço } \\
\text { físico, } \\
\text { postura } \\
\text { inadequada }\end{array}$ & $\begin{array}{l}\text { Incêndio, } \\
\text { explosão e } \\
\text { queimaduras }\end{array}$ \\
\hline CALHA & $\begin{array}{l}\text { Exposição } \\
\text { ao sol }\end{array}$ & Pó de ferro & $\begin{array}{l}\text { Postura } \\
\text { inadequada }\end{array}$ & $\begin{array}{l}\text { Queda de } \\
\text { altura e } \\
\text { máquina sem } \\
\text { proteção }\end{array}$ \\
\hline
\end{tabular}

Nele foi possível alocar, por setores, os riscos encontrados na empresa através da percepção dos colaboradores, subdividindo-os em físicos, químicos, como por exemplo o fumo de solda, que se trata de uma fumaça tóxica emitida pelo processo de soldagem, ergonômicos, de acidentes e biológicos, o que implementa a visualização em comparação a APR e facilita a análise dos dados, tornando possível a proposta de medidas de prevenção e propostas de melhorias a empresa. 
Os riscos biológicos não foram determinados devido a não realização de uma análise microbiológica durante o período de estudo na empresa.

\subsection{Medidas de prevenção e propostas de melhorias}

A partir da APR foi possível propor planos de ação para prevenção bem como melhorias a partir da aplicação da ferramenta $5 \mathrm{~W} 1 \mathrm{H}$ (Tabela 8 ).
Conforme observa-se na Tabela 8, o plano de ação proposto foi desenvolvido com a finalidade de minimizar os acidentes a partir dos riscos identificados. Além disso, baseou-se nos requisitos estabelecidos a partir do diretor da organização bem como de acordo com a realidade da empresa a fim de que este seja coerente com a situação vivenciada no cotidiano.

\begin{tabular}{|c|c|c|c|c|c|}
\hline $\begin{array}{l}\text { O quê? } \\
\text { (What) }\end{array}$ & $\begin{array}{l}\text { Quem } \\
\text { (Who) }\end{array}$ & $\begin{array}{c}\text { Onde } \\
\text { (Where) }\end{array}$ & $\begin{array}{l}\text { Quando } \\
\text { (When) }\end{array}$ & $\begin{array}{c}\text { Por quê } \\
(\text { Why })\end{array}$ & $\begin{array}{l}\text { Como } \\
\text { (How) }\end{array}$ \\
\hline $\begin{array}{l}\text { Utilização de } \\
\text { carrinho manual }\end{array}$ & Diretor & $\begin{array}{l}\text { setores de } \\
\text { pintura e } \\
\text { serralheria }\end{array}$ & Imediatamente & $\begin{array}{l}\text { Os trabalhadores destes setores identificaram o } \\
\text { transporte excessivo de peso como sendo } \\
\text { prejudicial à saúde }\end{array}$ & $\begin{array}{l}\text { Identificação das situações em que este } \\
\text { risco acontece e pesquisar no mercado qual } \\
\text { carrinho se adequa melhor as necessidades }\end{array}$ \\
\hline $\begin{array}{l}\text { Fichas de entrega } \\
\text { de EPIs }\end{array}$ & Diretor & $\begin{array}{l}\text { Todos } \\
\text { setores }\end{array}$ & Até dez. 2019 & $\begin{array}{l}\text { Para servir como um termo de compromisso e } \\
\text { responsabilidade pela entrega e uso dos EPIs } \\
\text { por parte dos colaboradores }\end{array}$ & $\begin{array}{l}\text { Ao entregar o EPI aos funcionários entregar } \\
\text { também a ficha e preencher com os seus } \\
\text { dados }\end{array}$ \\
\hline $\begin{array}{l}\text { Treinamentos para } \\
\text { o uso do EPI }\end{array}$ & Diretor & $\begin{array}{l}\text { Todos } \\
\text { setores }\end{array}$ & Até dez. 2019 & $\begin{array}{l}\text { Para conscientizar os colaboradores da forma } \\
\text { correta e da importância da utilização dos EPIs }\end{array}$ & $\begin{array}{l}\text { Ao entregar os EPIs, pesquisar no mercado } \\
\text { e alguma instituição que forneça tal } \\
\text { treinamento e agendá-lo }\end{array}$ \\
\hline $\begin{array}{l}\text { Programa de } \\
\text { ginastica laboral }\end{array}$ & Diretor & $\begin{array}{l}\text { Todos } \\
\text { setores }\end{array}$ & Até dez. 2019 & $\begin{array}{l}\text { Para conscientizar os colaboradores acerca da } \\
\text { postura no trabalho, e da importância do } \\
\text { alongamento antes das atividades na empresa }\end{array}$ & $\begin{array}{l}\text { Contratar educadores físicos para que } \\
\text { instruam os colaboradores nesses } \\
\text { exercícios, com frequência semanal }\end{array}$ \\
\hline $\begin{array}{lr}\text { Plano } & \text { de } \\
\text { manutenção } & \\
\text { preventiva } & \text { e } \\
\text { readequação } & \text { do } \\
\text { maquinário } & \\
\text { segundo NR-12 } & \end{array}$ & Diretor & $\begin{array}{l}\text { Setor de } \\
\text { serralheria, } \\
\text { soldagem e } \\
\text { pintura }\end{array}$ & Até dez. 2019 & $\begin{array}{l}\text { Para resolver os problemas com as máquinas e } \\
\text { equipamentos, onde os colaboradores } \\
\text { identificaram o risco de acidentes }\end{array}$ & $\begin{array}{l}\text { Contratar empresas que realizam a } \\
\text { implantação do plano de manutenção } \\
\text { preventiva e que instruam os colaboradores }\end{array}$ \\
\hline $\begin{array}{l}\text { Revitalização } \\
\text { iluminação } \\
\text { ventilação }\end{array}$ & Diretor & $\begin{array}{l}\text { Todos } \\
\text { setores }\end{array}$ & Imediatamente & $\begin{array}{l}\text { Para melhorar o bem estar e a disposição dos } \\
\text { colaboradores no dia a dia, e diminuir as } \\
\text { chances de acidentes }\end{array}$ & $\begin{array}{l}\text { Fazer um levantamento de pontos com } \\
\text { pouca iluminação e ventilação dentro da } \\
\text { empresa, e pesquisar no mercado lâmpadas } \\
\text { e climatizadores de ar }\end{array}$ \\
\hline $\begin{array}{l}\text { Realocação dos } \\
\text { equipamentos } \\
\text { (layout) }\end{array}$ & $\begin{array}{l}\text { Gerente } \\
\text { de } \\
\text { produção }\end{array}$ & $\begin{array}{l}\text { Setor de } \\
\text { serralheria e } \\
\text { soldagem }\end{array}$ & De imediato & $\begin{array}{l}\text { Para manter a segurança no desenvolvimento } \\
\text { das ações, onde estas máquinas consideradas } \\
\text { perigosas ficam alocadas de maneira aleatória }\end{array}$ & $\begin{array}{l}\text { Deixando-as distantes umas das outras, em } \\
\text { espaços maiores para o colaborador operá- } \\
\text { las e com sinalização em virtude do risco de } \\
\text { acidente }\end{array}$ \\
\hline
\end{tabular}

\section{Conclusões}

O presente estudo alcançou seu objetivo geral, sendo possível a partir da análise das percepções de risco com os colaboradores, identificar os riscos presentes nos processos da indústria metalúrgica analisada e definir planos de melhorias para os riscos identificados. Observou-se que os trabalhadores conseguiram identificar e relacionar os fatores de riscos ocupacionais a que estão expostos e os prejuízos que podem trazer à sua saúde.

A análise dos riscos com a aplicação da APR e a identificação das possíveis causas chegaram a resultados satisfatórios, onde conseguiu-se definir por setor da empresa os riscos como ruídos, máquinas e equipamentos sem proteção adequada, quedas, incêndios, explosões, esforço físico, postura inadequada, suas causas e efeitos, além de sua frequência e severidade de ocorrência, bem como seu nível.

Avaliando as informações sobre a percepção dos colaboradores da indústria é possível identificar informações relevantes e que devem ser usadas como benefícios não só destes colaboradores, como para a empresa de um modo geral. Espera-se que tanto colaboradores quanto responsáveis tomem conhecimento dos riscos a que estão sujeitos no desenvolvimento de suas funções.

Assim, com este estudo, foi possível compreender que o ambiente de trabalho, quando inadequado, pode ser um agravante para as doenças ocupacionais, deixando um conceito para a conscientização sobre qualidade de vida no trabalho e com os 
planos de ações sugeridos devem ocorrer melhorias envolvendo a ergonomia e segurança do trabalho, tornando essa pesquisa fonte de informações que podem solucionar dúvidas e problemas enfrentados no dia a dia da empresa, demonstrando a importância de sua execução.

\section{PERCEPTION OF RISKS AT WORK: A CASE STUDY WITH A METALLURGICAL INDUSTRY COLABORATORS}

ABSTRACT: The health and safety of an individual in his work environment and as conditions provided by the company directly reflect on his production and not personal well-being during the actions that he exercises. Thus, this study aims to analyze the perception of risks without work with employees of a metallurgical company located in the northwest of the state of Paraná. The exploratory and basic research methodology, implemented with the help of a questionnaire applied to the collaborators, was adopted as methodology. For the development of information, follow the steps of preparing the bibliography, gathering information and characterizing the company, collecting and analyzing the data, evaluating safety equipment, preparing the preliminary risk analysis and, finally, proposing improvements to the risks identified by employees. As a result, the risks presented by our employees based on employees' perceptions are identified, such as inadequate use of PPE, risk of falls and intoxication as well as noise. From then on, they make improvements. In this way, it was possible to conclude that as situations identified by analyzes, the safety and health of the employees of this company are at risk, and that due attention should be paid by those responsible for the organization.

Keywords: Work safety. Risk analysis. Metallurgical industry.

\section{Referências}

[1] FÉLIX, J. C. et al. M. Proposição de melhorias em segurança por meio da aplicação do FMEA: Um estudo de caso em uma empresa do setor ferroviário, Tecno-Lógica, Vol. 22, n. 2, p. 147-156, 2018.

[2] PEREIRA, N. F. S. et al. Melhoria ergonômica em postos de trabalho do setor de acabamento de uma fundição através do método OWAS de análise de postura. Revista Eletrônica Produção \& Engenharia, Vol. 4, n. 2, p. 403-411. 2013.

[3] AREOSA, J.; DWYER, T. Acidentes de trabalho: uma abordagem sociológica. Configurações, n. 7, p.107-128, 2010.

[4] LOUSA, Ana Rita Bolinhas. Identificação de Perigos e Avaliação de Riscos Profissionais de uma Oficina Automóvel. 2014. 66 f. Dissertação (Mestrado) Curso de Técnico Superior de Segurança e Higiene no Trabalho, Instituto Politécnico de Setúbal, Setúbal. 2014.

[5] PREVIDÊNCIA SOCIAL. Anuário Estatístico 2015. Disponível em:<http://www.previdencia.gov.br/wp-content/uploads/2015/08/AEPS-2015-

FINAL.pdf.> Acesso em: 02 out. 2018.
[6] FRANÇA, S. L. B; TOZE, M. A; QUELHAS, O. L. G. A gestão de pessoas como contribuição à implantação da gestão de riscos. O caso da indústria da construção civil. Revista Produção Online, Vol. 8, n. 4, dez. 2008.

[7] OLIVEIRA, J.C. Segurança e saúde no trabalho: uma questão mal compreendida. São Paulo. Revista São Paulo em Perspectiva, Vol. 17, n. 2. 2010.

[8] HEALTH AND SAFETY EXECUTIVE. Risk assessment: A brief guide to controlling risks in the workplace. Healthand Safety Executive, United Kingdom, 2014. EXECUTIVO DE SAÚDE E SEGURANÇA. Avaliação de risco: Um breve guia para o controle de riscos no local de trabalho. Health and Safety Executive, Reino Unido, 2014

[9] ILVA, A.C. Mapeamento de risco em uma padaria. 2011 53f. Monografia (Engenharia de Segurança do Trabalho) - Universidade Regional do Noroeste do Estado do Rio Grande do Sul, Santa Rosa/RS, 2011.

[10] LIMA, V. F.; LIMA, L. E. M. Gestão de segurança do trabalho na indústria de papel: diagnóstico de cultura de segurança por meio de pesquisa de identificação de nível de segurança. R. Gestão Industrial, Vol. 13, n. 4, p. 205-222. 2017.

[11] SHERIQUE, Jaques. Aprenda como fazer: APR. 7 ed. São Paulo: LTr 2011.

[12] QUEIROZ, Willian F. L. de. Análise dos aspectos de segurança em um laboratório de corrosão: um estudo de caso. 2013. 80 f. Monografia de Conclusão do Curso de Pós-Graduação em Engenharia de Segurança do Trabalho da Universidade Federal Fluminense, 2013.

[13] ARAÚJO, Wellington Tavares de. Manual de Segurança do Trabalho. São Paulo: DCL, 2010.

[14] GIL, A. C. Métodos e técnicas de pesquisa social.5. Ed. São Paulo: Atlas, 2010

[15] BONATTO, F.; et al. Aplicação das ferramentas da qualidade para melhoria do controle de estoque de uma mercearia. In: VIII CONBREPRO, Congresso Brasileiro de Engenharia de Produção, 8, Ponta Grossa, dezembro 2018. 


\section{Apêndices \\ Apêndice A - Questionário}

\section{Identificação pessoal}

1-Nome:

2-Faixa etánia/Idade:

() de 16 à 20 anos

() de 20 à 30 anos

() de 30 à 40 anos

() de 40 à 50 anos

() acima de 50 anos

Idade:

3-Setor de atuação:

() Administrativo

() Pintural

() Serralheria

() Soldagem

() Calhas e rufos

4-Escolaridade:

() Analfabeto

() Alfabetizado

() Ensino Fundamental Incompleto

() Ensino Fundamental Completo

() Ensino Médio Incompleto

() Ensino Médio Completo

() Ensino Superior Incompleto

() Ensino Superior Completo

() Curso Técnico de Nivel Médio

() Curso Técnico de Nível Superior

Curso Técnico. Qual?
Quanto a atividade profissional

5-Sofreu acidente de trabalho:

() SIM

() NÃO

Caso sim, qual?

Caso sim, onde?

6-Sente-se desprotegido durante as atividades do dia a dia

() SIM

() NÃO

Caso sim, qual ambiente ou má quina the causa mais precaução?

7- Quanto tempo trabalha na Indústria

() menos de 01 ano

() de 01 á 03 anos

() de 03 à 6 anos

() de 06 á 10 anos

() mais de 10 anos

8- Como você avalia a prestação de serviço no que diz respeito a segurança no trabalho dentro da indústria:

() Péssima

() Ruim

() Regular

() Boa

() Ótima

() Excelente

9- Com relação ao ambiente ou qual máquina the causam mais precaução?

10- Quais seriam para você as situações críticas vivenciadas no dia-dia de trabalho:

( ) Ruídos

() Postura Inadequada

( ) Esforço físico

() Transporte de material

() Conforto térmico no trabalho

( ) Conforto visual no trabalho

() Possivel choque elétrico

()Falta de manutenção das máquinas/equipamentos

( ) Excesso de jomada de trabalho

Caso outro, explique?

11 - O que poderia ser melhorado para evitar ou eliminar os riscos de sua função e da empresa, caso tenha? 


\section{Apêndice B - Termo de consentimento livre e esclarecido}

Gostaríamos de convidá-lo a participar da pesquisa intitulada "ANÁLISE SOBRE A PERCEPÇÃO DE RISCOS NO TRABALHO COM COLABORADORES DE UMA INDÚSTRIA METALÚRGICA", que faz parte do trabalho de conclusão de curso do acadêmico Dener de Souza, do Departamento de Engenharia de Produção que é orientado pela professora Ana Carla Femandes Gasques da Universidade Estadual de Maringá. O objetivo da pesquisa é analisar conforme a percepção dos colaboradores os riscos presentes nos processos produtivos de uma indústria metalúrgica e a partir de então elaborar uma análise preliminar dos riscos e propor planos de melhoria a cada risco encontrado. Para isto a sua participação é muito importante, e ela se daria da seguinte forma: Respondendo o questionário proposto que conta com 10 questões de cunho pessoaḷ e profissional, que são extremamente relevantes para o desenvolvimento do trabalho e necessitam da coesão $e$ honestidade em todas as respostas. Informamos que poderão ocorrer os riscos/desconfortos a seguir, como constrangimento em relação ao fomecimento dos dados pessoais, como também incômodo em relação às questões do âmbito profissional, uma vez que são questões que levam a opinião individual de cada colaborador sobre o processo produtivo, estrutura $e$ qualificações da empresa. Gostaríamos de esclarecer que sua participação é totalmente voluntária, podendo você: recusar-se a participar, ou mesmo desistir a qualquer momento sem que isto acarrete qualquer ônus ou prejuízo à sua pessoa. Informamos ainda que as informações serão utilizadas somente para os fins desta pesquisa, e serão tratadas com o mais absoluto sigilo e confidencialidade, de modo a preservar a sua identidade. Os benefícios esperados com essa análise é a identificação dos riscos a que os colaboradores como você estão sujeitos, prevenindo desta forma a ocorrência de acidentes de trabalho, proporcionando melhores condições de trabalho e bem-estar. Caso você tenha mais dúvidas ou necessite maiores esclarecimentos, pode nos contatar nos endereços abaixo ou procurar o Comitê de Ética em Pesquisa da UEM, cujo endereço consta deste documento.

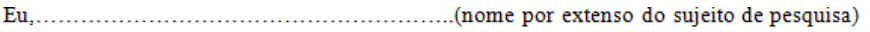
declaro que fui devidamente esclarecido e concordo em participar VOLUNTARIAMENTE da pesquisa coordenada pelo acadêmico Dener de Souza.

Data:

Assinatura ou impressão datiloscópica

Eu, . Dener de Souza, declaro que formeci todas as informações referentes ao projeto de pesquisa supra-nominado.

Data:

Assinatura do pesquisador

Qualquer dúvida com relação à pesquisa poderá ser esclarecida com o pesquisador,

conforme o endereço abaixo:

Nome: Dener de Souza

Endereço: Rua Maria Rui Testa, $n^{\circ} 71$

(telefone/e-mail): Denersfc2010@gmail.com 